\title{
Recent snowfall anomalies in Dronning Maud Land, East Antarctica, in a historical and future climate perspective
}

\author{
Jan T. M. Lenaerts, ${ }^{1}$ Erik van Meijgaard, ${ }^{2}$ Michiel R. van den Broeke, ${ }^{1}$ \\ Stefan R. M. Ligtenberg, ${ }^{1}$ Martin Horwath, ${ }^{3}$ and Elisabeth Isaksson ${ }^{4}$ \\ Received 1 May 2013; revised 10 May 2013; accepted 10 May 2013; published 7 June 2013.
}

[1] Enhanced snowfall on the East Antarctic ice sheet is projected to significantly mitigate 21 st century global sea level rise. In recent years (2009 and 2011), regionally extreme snowfall anomalies in Dronning Maud Land, in the Atlantic sector of East Antarctica, have been observed. It has been unclear, however, whether these anomalies can be ascribed to natural decadal variability, or whether they could signal the beginning of a long-term increase of snowfall. Here we use output of a regional atmospheric climate model, evaluated with available firn core records and gravimetry observations, and show that such episodes had not been seen previously in the satellite climate data era (1979). Comparisons with historical data that originate from firn cores, one with records extending back to the 18th century, confirm that accumulation anomalies of this scale have not occurred in the past $\sim 60$ years, although comparable anomalies are found further back in time. We examined several regional climate model projections, describing various warming scenarios into the 21 st century. Anomalies with magnitudes similar to the recently observed ones were not present in the model output for the current climate, but were found increasingly probable toward the end of the 21 st century. Citation: Lenaerts, J. T. M., E. van Meijgaard, M. R. van den Broeke, S. R. M. Ligtenberg, M. Horwath, and E. Isaksson (2013), Recent snowfall anomalies in Dronning Maud Land, East Antarctica, in a historical and future climate perspective, Geophys. Res. Lett., 40, 2684-2688, doi:10.1002/grl.50559.

\section{Introduction}

[2] In a warming climate, increasing snowfall on the Antarctic ice sheet is likely to mitigate 21 st century sea level rise, with a projected mitigation of 30 to $70 \mathrm{~mm}$ sea level equivalent by 2100 [Krinner et al., 2007; Bengtsson et al., 2011; Ligtenberg et al.. 2013]. In the recent decades, however, no significant trend in snowfall has been observed [Monaghan, et al., 2006; Lenaerts et al., 2012; Frezzotti et al., 2013], apart from locally increased or decreased

Additional supporting information may be found in the online version of this article.

${ }^{1}$ Institute for Marine and Atmospheric Research Utrecht, Utrecht, Netherlands.

${ }^{2}$ Royal Netherlands Meteorological Institute, De Bilt, Netherlands.

${ }^{3}$ Institut für Astronomische und Physikalische Geodäsie, Technische Universität München, München, Germany.

${ }^{4}$ Norwegian Polar Institute, Tromsø, Norway.

Corresponding author: J. T. M. Lenaerts, Institute for Marine and Atmospheric Research Utrecht, Utrecht University, 5 Princetonplein, NL3584 CC Utrecht, Netherlands. (jtmlenaerts@gmail.com)

(C2013. American Geophysical Union. All Rights Reserved. 0094-8276/13/10.1002/grl.50559 accumulation [Isaksson et al., 1999; Thomas et al., 2008]. Because inter-annual variations in snowfall are large $(\sim 30 \%$ on a continental scale, Van Lipzig et al. [2003]; Reijmer et al. [2004]), any short-term accumulation anomaly may be the result of natural, inter-annual variations, rather than an indication of a long-term signal. Such a large snowfall anomaly occurred in Dronning Maud Land (DML, East Antarctica), in the first half of 2009. The Gravity Recovery and Climate Experiment (GRACE) satellites observed a mass increase of $\sim 160 \mathrm{Gt}$ during this period [Boening et al., 2012]. Concurrently, ENVISAT altimetry revealed surface elevation increases of up to $1 \mathrm{~m}$ [Shepherd et al., 2012]. In the absence of significant changes in the ice discharge in DML [Rignot et al., 2011], and little interannual variability in the other surface mass balance (SMB) components, i.e., rainfall, sublimation, and zero runoff [Lenaerts et al., 2012], this anomaly can be fully ascribed to anomalously high snowfall [Shepherd et al., 2012; Boening et al., 2012]. In situ measurements at the Belgian Princess Elisabeth base $\left(72^{\circ} \mathrm{S}, 21^{\circ} \mathrm{E}\right)$ confirm a surface mass balance of $250 \mathrm{~mm}$ w.e. in January-June 2009, whereas the subsequent 1.5 years show no accumulation at all [Gorodetskaya et al., 2013]. Another anomalous snowfall episode was detected two years later, in 2011 [Boening et al., 2012]. However, most observational time series are too short to judge whether these anomalies can be ascribed to natural variability, or whether they may be a first signal of the projected increase in snowfall owing to global warming.

[3] Here we combine output from a regional atmospheric climate model at $27 \mathrm{~km}$ resolution (1979-2012) with GRACE mass anomalies and accumulation estimates from firn cores to reconstruct a long-term surface mass balance climate of Dronning Maud Land. This allows us to better estimate the natural, inter-annual snowfall variability and extremes. To compare observed variability with projected changes in the DML SMB during the remainder of the 21st century, we also analyze RACMO2 output driven by different General Circulation Models (GCMs) and different climate warming scenarios.

\section{Data}

[4] In this study, we use the regional atmospheric climate model RACMO2 (see supporting information) at a horizontal resolution of $27 \mathrm{~km}$ [Lenaerts et al., 2012], driven by atmospheric fields, sea-surface temperatures, and sea-ice extent of ERA-Interim reanalyses (1979-July 2012). SMB from RACMO2 is validated using RL05 GRACE mass anomalies (2003-July 2012, see supporting information) and a compiled SMB dataset from available firn cores 

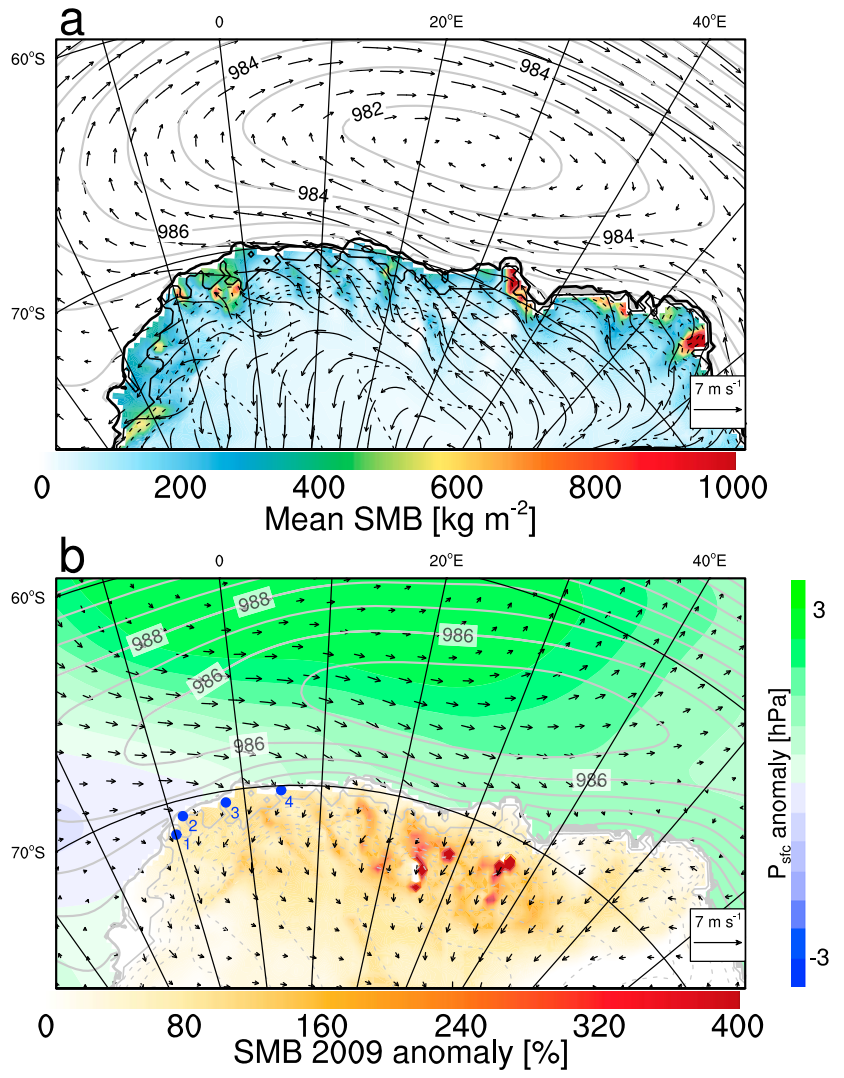

Figure 1. (a) Simulated 1979-2011 mean of surface pressure distribution (grey lines, in $\mathrm{hPa}$ ) on the ocean, and near-surface wind field (arrows) and SMB on the ice sheet. (b) Simulated surface pressure distribution (grey lines, in $\mathrm{hPa}$ ) in 2009, and 2009 anomalies (with respect to 1979-2011 mean) of surface pressure (green-blue, in $\mathrm{hPa}$ ), and SMB (in \%). The locations of the firn cores (Figure 4) are indicated in blue with their respective numbers $(1-4)$.

[Rotschky et al., 2007]. Historical SMB data are used from selected firn cores from this data set, providing a sufficiently long historical SMB data set and a near-coastal location (see supporting information).

\section{Results}

\subsection{Surface Mass Balance in Dronning Maud Land}

[5] Dronning Maud Land is characterized by rough topography, especially near the coast. Even on its ice shelves, which are relatively flat, small-scale ice rises strongly control accumulation patterns [Rotschky et al., 2007]. On the grounded ice sheet, alternating ridges and troughs impact the distribution of snow through orographic effects and wind-related sublimation and redistribution [Reijmer et al., 2004; Thiery et al., 2012]. Blue-ice areas, where annual snow sublimation and erosion exceed annual snowfall, are common in Dronning Maud Land [Bintanja, 1999; Winther et al., 2001; Van den Broeke et al., 2006]. Even on spatial scales smaller than $1 \mathrm{~km}$, accumulation may vary substantially [Richardson and Holmlund, 1999; Isaksson et al., 1999]. These small-scale heterogeneities are not represented, but the large-scale patterns of spatial SMB variability are well reproduced in RACMO2 (Figure 1a).
[6] Both snowfall rate and wind-related processes are strongly controlled by the direction and strength of the atmospheric flow in the free atmosphere and the atmospheric boundary layer. Figure 1a illustrates that katabatic forcing is the main driver of the wind close to the ice sheet surface, as the winds predominantly descend from the high, dry interior towards the margin, deflected to the left by the Coriolis effect. The climatological mean low-pressure system over the southern Atlantic Ocean, centered around $25^{\circ} \mathrm{E}$, forces an easterly atmospheric flow along the DML coast, bringing moisture and precipitation to eastward facing slopes of north-south directed topographic barriers (Figure 1a).

\subsection{The 2009 Accumulation Anomaly}

[7] Not only spatial but also temporal variability of Antarctic SMB is significant [Lenaerts et al., 2012], especially in DML [Oerter et al., 2000; Kaczmarska et al., 2004], where high-precipitation events are strongly episodic in nature [Schlosser et al., 2008, 2010]. This variability is strongly controlled by the atmospheric circulation [Reijmer et al., 2004]. Figure 1b shows that in 2009, the low-pressure system in the southern Atlantic was weaker. Instead, anomalously low pressure in the eastern Weddell Sea sector promoted southward atmospheric flow over DML. Also on the ice sheet, the anomalous wind vectors are directed towards the south (Figure 1b). This persistent atmospheric circulation anomaly caused the 2009 SMB anomaly in DML. Concurrently, atmospheric reanalyses reveal (not shown) that sea surface temperatures were anomalously high in the subtropical [Foltz et al., 2011] and sub-polar southern Atlantic ocean, the major source region for Dronning Maud Land precipitation [Reijmer and van den Broeke, 2001]. These high SSTs may have enhanced evaporation over the Atlantic, increasing moisture content of the air advected toward the south. Note the large spatial extent of the accumulation anomaly: it is found in the entire DML sector, from $20^{\circ} \mathrm{W}$ to $60^{\circ} \mathrm{E}$, and from the coast up to higher elevations in the interior, with anomalies ranging from 50 to $400 \%$. The highest anomalies ( $>$ two times the mean) are simulated in the escarpment regions (500-1500 m elevation) in central DML $\left(10-40^{\circ} \mathrm{E}\right)$.

[8] Figure 2a shows that the peak value and duration of the 2009 SMB anomaly, when integrated over the three DML drainage basins [Shepherd et al., 2012], are unprecedented in the period 1979-2011. Especially the first half of 2009 experienced a prolonged wet period [Boening et al., 2012], with 4 out of the 6 months experiencing more than two times the average SMB for that month, and three out of the six (January, May, and June) more than three times the 19792011 mean. Also, September and October 2009 had high SMB values, whereas the other months had near-average SMB. The timing and magnitude of the anomaly simulated by RACMO2 agree within the uncertainties with the GRACE solutions (Figure 2b), yielding a total cumulative mass anomaly within one $\sigma$ of $118 \pm 46 \mathrm{Gt}$ (RACMO2) and $169 \pm 31$ (GRACE) during 2009 in DML [Shepherd et al., 2012; Boening et al., 2012]. The second anomaly in 2011 is also significant, but smaller than in 2009, both in RACMO2 $(107 \pm 60 \mathrm{Gt})$ and GRACE $(135 \pm 31 \mathrm{Gt})$. These anomalies in DML occurred on a drainage basin scale, and no similar anomalies were found in the remainder of East Antarctica. Figure 2c shows that the 2003-2012 SMB anomalies for East Antarctica, while positive in DML, were strongly negative in 

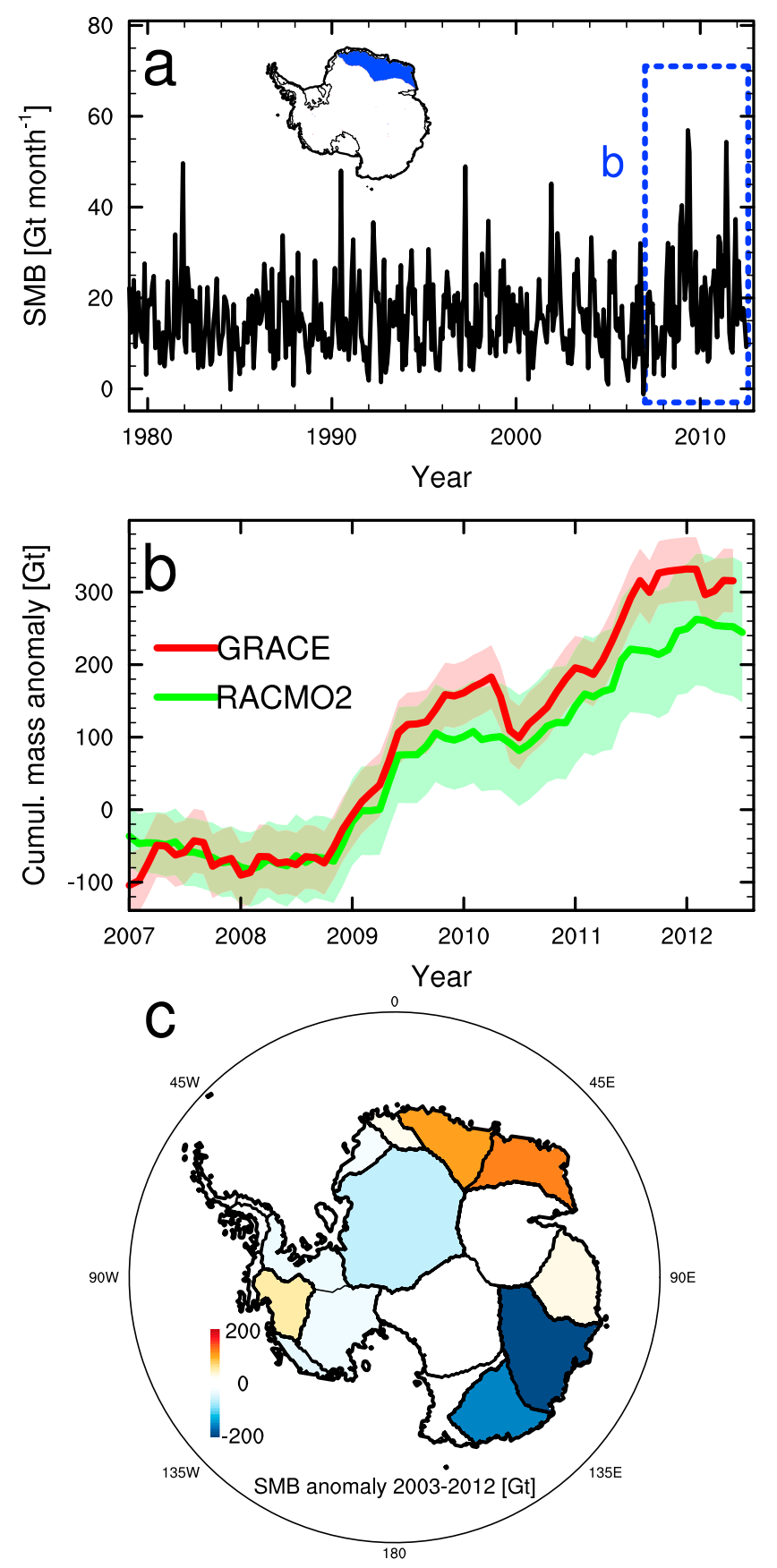

Figure 2. (a) RACMO2 SMB (Gt per month) in DML (IMBIE IceSAT basins 5-8 in Shepherd et al. [2012], indicated in blue in inset map) for January 1979 to July 2012. (b) Cumulative mass anomaly (Gt) for the same basins from GRACE (red) and RACMO2 (green) in January 2007-August 2012 (blue box in Figure 2a). The color-shaded areas show the related uncertainty $(2 \sigma)$ in GRACE (red) and RACMO2 (green). (c) Simulated SMB cumulative anomaly for the period January 2003 to January 2012 in each Antarctic drainage basin. For RACMO2, we use the period 1979-2002 as reference period to calculate the SMB anomaly (see text).

the Wilkes land and Adélie Land sector $\left(120-160^{\circ} \mathrm{E}\right)$, another region that is prone to strong interdecadal SMB variability [Agosta et al., 2012].

[9] Recent studies pointed toward the strong relation between Antarctic near-surface temperature and SMB [e.g.,
Krinner et al., 2007; Ligtenberg et al., 2013]. Although DML experienced a relatively warm year in 2009 and 2011 according the RACMO2 time series (near-surface temperature was $\sim 2 \mathrm{~K}$ warmer than average), other similarly warm years did not yield a similar SMB anomaly (Figure S1). No significant relation is found between DML near-surface temperature and SMB, which demonstrates that the DML climate is not only driven by (local) near-surface temperatures but also by larger-scale circulation anomalies.

[10] The following analysis focuses on the largest anomaly in DML of the year 2009 only. Other observational proof of this exceptional anomaly is presented in Figure 3a, which compares the zonally stacked accumulation records from 128 firn cores [Rotschky et al., 2007], with colocated SMB estimates of RACMO2. The long-term mean of RACMO2 compares well with the firn cores, apart from a model
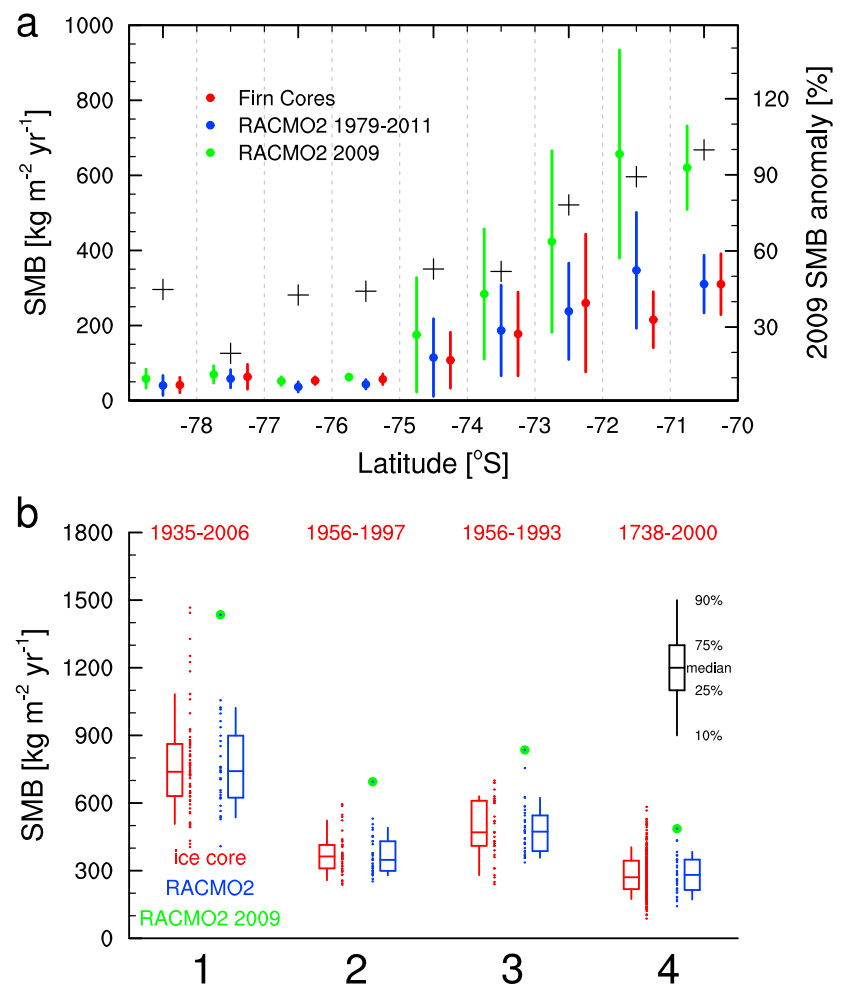

Figure 3. (a) Annual SMB, binned per $1^{\circ}$ latitude, measured in the firn cores (red), RACMO2 average SMB (1979-2011) (blue), and RACMO2 SMB in the year 2009 (green). The vertical lines denote the spatial variability within the latitudinal bins (length is $2 \sigma$ ). Black crosses (right axis) show the simulated relative anomaly of the SMB in 2009 compared to the 1979-2011 average. (b) Comparison of multi-year SMB from firn cores (red) at four locations, which are indicated in Figure 1. Firn core data originate, from left to right, from Fernandoy et al. [2010] (core B39), Isaksson et al. [1999] (S20), Melvold et al. [1998] (H), and Kaczmarska et al. [2004] (S100). The 1979-2011 RACMO2 SMB distribution for the nearest model grid point is shown in blue. The dots show all available SMB values, and the box plot shows the temporal characteristics of the time series. The uppermost and lowermost boundaries are the 90 and 10 percentiles, respectively (see black box plot for legend). The RACMO2 2009 SMB is shown by the green marker, and the period representing the ice core is indicated in red. 


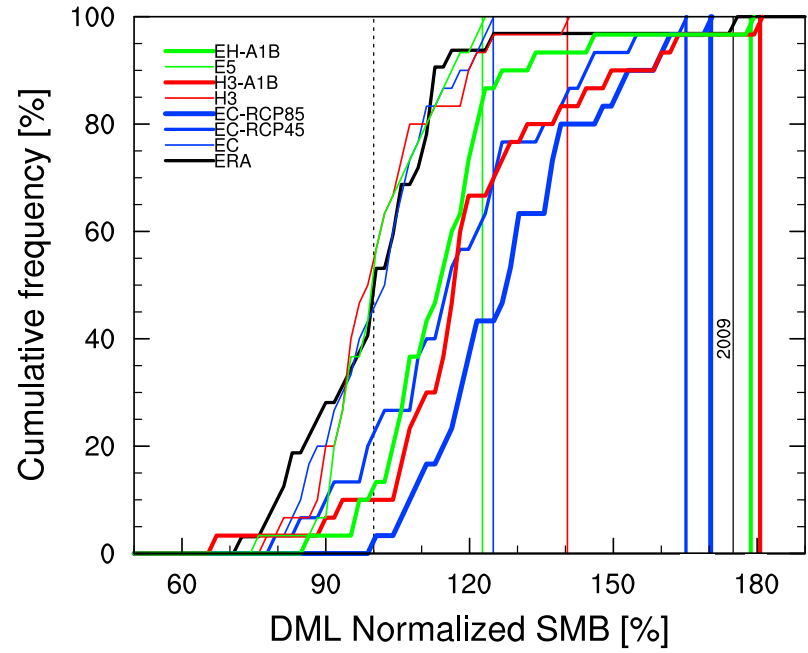

Figure 4. Cumulative probability distribution (\%) of normalized basin-integrated SMB (ICESat basins 5-8 [Shepherd et al., 2012, see Figure 2a]) according to RACMO2 forced by ERA-Interim reanalyses (black, 2009 indicated with vertical black line), and according to various GCMs and scenarios (see Table S1 for details). The period $1970-2000$ is used as a reference period to normalize the SMB. The thin solid lines represent the historical simulations (1970-2000); the thick solid lines are the projections (2070-2100). The vertical lines mark the SMB of the year with the highest SMB in each 31 year period.

overestimation in the $71^{\circ}$ latitudinal band, and the positive SMB gradient towards the coast is well simulated. Clearly, 2009 has been relatively wet in all latitudinal bands in DML, with a positive SMB anomaly of $20-50 \%$ on the inland portions, and an SMB approximately double the long-term mean in the coastal latitudinal bands (Figure 3a).

\subsection{The 2009 Anomaly in a Longer Historical Context (1738-present)}

[11] Figure 2a indicates that an annual SMB anomaly similar to 2009 has not been recorded since the beginning of the satellite era (1979). However, it remains unanswered whether this anomaly is part of longer term natural variability or if it signals increasing Antarctic SMB following from increasing atmospheric temperatures. Figure $3 \mathrm{~b}$ compares annual SMB from the four long-term firn cores with the 33 years of model-derived SMB at four coastal locations in DML. It shows that the 2009 anomaly greatly exceeds the temporal standard deviation at all four coring locations, being more than $20 \%$ larger than the 90 percentile derived from the firn cores. In the cores that only go back to the 1950s (cores 2 and 3), there is no year that had an SMB similar to that of 2009. However, in the deeper cores, one of which goes back to the 18th century [Kaczmarska et al., 2004], we find several years with a 2009-like SMB. Note that according to Figure 1b, SMB anomalies increase towards the east, and the four selected cores are outside the region of the largest anomalies. These results suggest that an anomaly such as in 2009 did not occur in Dronning Maud Land for at least several decades, but further back in time, there were years with SMB similar to that of the year 2009.

\subsection{Future Climate}

[12] Finally, we used SMB anomalies from GCM-forced future RACMO2 simulations. We compared the 31 year period 2070-2100 and 1970-2000 (Table 1), to analyze whether extreme accumulation years may be increasing in frequency in the coming century. Figure 4 shows the cumulative probability distribution of normalized SMB (with respect to the period 1970-2000) in the DML basins. First, the contemporary portions in the scenario runs (thin lines) have an SMB probability distribution similar to the ERA-Interim forced run (thin black line). For the present-day climate, none of the GCM-forced runs shows the occurrence of an extreme year similar to 2009 (thin vertical lines). All scenario runs agree that at the end of the 21 st century, at least 1 year will occur with DML SMB 55-80\% larger than the present-day mean SMB (heavy vertical lines). This not only results from a gradual increase in SMB with rising temperatures but also owing to the highend tail of the probability distribution becoming longer (heavy lines), implying a shift toward larger probabilities of high-accumulation episodes to occur (Figure 4). However, none of the future extreme accumulation years does show a near-surface circulation anomaly similar to that observed in 2009 .

\section{Discussion and Conclusions}

[13] The entirety of Dronning Maud Land (East Antarctica) experienced a large snowfall and hence positive SMB anomaly in the year 2009. This episode was driven by anomalous large-scale atmospheric conditions that enhanced the poleward transport of moisture. Although similar circulation patterns regularly occurred in the period 2001-2006 as well [Schlosser et al., 2010], these persisted throughout much of the first half of 2009 [Boening et al., 2012]. Due to the lack of long climate and SMB time series, it has remained unclear how rare this anomaly was and whether it may signal an SMB increase in East Antarctica through atmospheric warming. In this study, we used output from a regional atmospheric climate model, driven by ERA-Interim (1979-2012), to show that the 2009 snowfall episode is unprecedented since 1979. Firn cores revealing the SMB history back to the 18th century indicate that a SMB anomaly similar to that of 2009 did not occur in DML in the last 60 years or so, but probably did occur further back in time. The future likelihood of such anomalies is studied using the regional climate model forced by several future GCM-driven climate change scenarios (A1B, RCP 4.5, and RCP 8.5). The results suggest that the end of this century will experience years with SMB values that are similar to the SMB observed in 2009. Attributing these future anomalies to either a warmer atmosphere or circulation anomalies remains speculative, due to the small sample size in combination with the wide range in regional responses between models and scenarios to increasing temperature, such as the rate of increase in precipitation [Ligtenberg et al., 2013], shifts in large-scale weather circulations [Fyfe and Saenko, 2006], and changes in seaice cover [Bintanja et al., 2013].

[14] Acknowledgment. The Editor thanks two anonymous reviewers for their assistance in evaluating this paper. 


\section{References}

Agosta, C., V. Favier, C. Genthon, H. Gallée, G. Krinner, J. T. M. Lenaerts, and M. R. van den Broeke (2012), A new surface accumulation dataset for Adélie Land, Antarctica $\left(66^{\circ} \mathrm{S}, 139^{\circ} \mathrm{E}\right)$ : Application for model validation, Clim. Dyn., 38(1-2), 75-86, doi:10.1007/s00382-011-1103-4.

Bengtsson, L., S. Koumoutsaris, and K. Hodges (2011), Large-scale surface mass balance of ice sheets from a comprehensive atmospheric model, Surv. Geophys., 32(4), 459-474, doi:10.1007/s10712-011-9120-8.

Bintanja, R. (1999), On the glaciological, meteorological and climatological significance of Antarctic blue ice areas, Rev. Geophys., 37(3), 337-359.

Bintanja, R., G. J. van Oldenborgh, S. S. Drijfhout, B. Wouters, and C. A. Katsman (2013), Important role for ocean warming and increased ice-shelf melt in Antarctic sea-ice expansion, Nat. Geosci., 6(5), 376-379, doi:10.1038/ngeo1767.

Boening, C., M. Lebsock, F. Landerer, and G. Stephens (2012), Snowfalldriven mass change on the East Antarctic ice sheet, Geophys. Res. Lett., 39, L21501, doi:10.1029/2012GL053316.

Fernandoy, F., H. Meyer, H. Oerter, F. Wilhelms, W. Graf, and J. Schwander (2010), Temporal and spatial variation of stable-isotope ratios and accumulation rates in the hinterland of Neumayer station, East Antarctica, J. Glaciol., 56(198), 673-687, doi:10.3189/002214310793146296.

Foltz, G. R., M. J. McPhaden, and R. Lumpkin (2011), A strong Atlantic meridional mode event in 2009: The role of mixed layer dynamics, J. Clim., 25(1), 363-380.

Frezzotti, M., C. Scarchilli, S. Becagli, M. Proposito, and S. Urbini (2013), A synthesis of the Antarctic surface mass balance during the last $800 \mathrm{yr}$, Cryosphere, 7(1), 303-319, doi:10.5194/tc-7-303-2013.

Fyfe, J. C., and O. A. Saenko (2006), Simulated changes in the extratropical Southern Hemisphere winds and currents, Geophys. Res. Lett., 33, L06701, doi:10.1029/2005GL025332.

Gorodetskaya, I. V., N. P. M. Van Lipzig, M. R. Van den Broeke, A. Mangold, W. Boot, and C. H. Reijmer (2013), Meteorological regimes and accumulation patterns at Utsteinen, Dronning Maud Land, East Antarctica: Analysis of two contrasting years, J. Geophys. Res., 118, 1700-1715, doi:10.1002/jgrd.50177.

Isaksson, E., M. van den Broeke, J.-G. Winther, L. Karlöf, J.-F. Pinglot, and N. Gundestrup (1999), Accumulation and proxy-temperature variability in Dronning Maud Land, Antarctica, determined from shallow firn cores, Ann. Glaciol., 29, 17-22.

Kaczmarska, M., et al. (2004), Accumulation variability derived from an ice core from coastal Dronning Maud Land, Antarctica, Ann. Glaciol., 39(1), 339-345, doi:10.3189/172756404781814186.

Krinner, G., O. Magand, I. Simmonds, C. Genthon, and J.-L. Dufresne (2007), Simulated Antarctic precipitation and surface mass balance at the end of the twentieth and twenty-first centuries, Clim. Dyn., 28(2-3), $215-230$.

Lenaerts, J. T. M., M. R. van den Broeke, W. J. van de Berg, E. Van Meijgaard, and P. Kuipers Munneke (2012), A new, highresolution surface mass balance map of Antarctica (1979-2010) based on regional atmospheric climate modeling, Geophys. Res. Lett., 39 , L04501, doi:10.1029/2011GL050713.

Ligtenberg, S. R. M., W. J. van de Berg, M. R. van den Broeke, J. G. L. Rae, and E. van Meijgaard (2013), Future surface mass balance of the Antarctic ice sheet and its influence on sea level change, simulated by a regional climate model, Clim. Dyn. (online first), doi:10.1007/s00382-013-1749-1.
Melvold, K., J. Hagen, J. Pinglot, and N. Gundestrup (1998), Large spatial variation in accumulation rate in Jutulstraumen ice stream, Dronning Maud Land, Antarctica, Ann. Glaciol., 27, 231-238.

Monaghan, A., et al. (2006), Insignificant change in Antarctic snowfall since the International Geophysical Year, Science, 313, 827-831.

Oerter, H., F. Wilhelms, F. Jung-Rothenhäusler, F. Göktas, H. Miller, W. Graf, and S. Sommer (2000), Accumulation rates in Dronning Maud Land, Antarctica, as revealed by dielectric-profiling measurements at shallow firn cores, Ann. Glaciol., 30, 27-34.

Reijmer, C. H., and M. R. van den Broeke (2001), Moisture sources of precipitation in Western Dronning Maud Land, Antarctica, Antarct. Sci., 13(2), 210-220.

Reijmer, C., E. van Meijgaard, and M. van den Broeke (2004), Numerical studies with a regional atmospheric climate model based on changes in the roughness length for momentum and heat over Antarctica, Boundary Layer Meteorol., 111(2), 313-337.

Richardson, C., and P. Holmlund (1999), Spatial variability at shallow snowlayer depths in central Dronning Maud Land, Antarctica, Ann. Glaciol., 29, 10-16.

Rignot, E., I. Velicogna, M. R. van den Broeke, A. Monaghan, and J. T. M. Lenaerts (2011), Acceleration of the contribution of Greenland and Antarctic ice sheets to sea level rise, Geophys. Res. Lett., 38, L05503, doi:10.1029/2011GL046583.

Rotschky, G., P. Holmlund, E. Isaksson, R. Mulvaney, H. Oerter, M. R. Van Den Broeke, and J.-G. Winther (2007), A new surface accumulation map for western Dronning Maud Land, Antarctica, from interpolation of point measurements, J. Glaciol., 53(182), 385-398, doi:10.3189/ 002214307783258459

Schlosser, E., M. G. Duda, J. G. Powers, and K. W. Manning (2008), Precipitation regime of Dronning Maud Land, Antarctica, derived from Antarctic Mesoscale Prediction System (AMPS) archive data, J. Geophys. Res., 113, D24108, doi:10.1029/2008JD009968.

Schlosser, E., K. W. Manning, J. G. Powers, M. G. Duda, G. Birnbaum, and K. Fujita (2010), Characteristics of high-precipitation events in Dronning Maud Land, Antarctica, J. Geophys. Res., 115, D14107, doi:10.1029/ 2009JD013410.

Shepherd, A., et al. (2012), A reconciled estimate of ice-sheet mass balance, Science, 338(6111), 1183-1189, doi:10.1126/science.1228102.

Thiery, W., I. V. Gorodetskaya, R. Bintanja, N. P. M. Van Lipzig, M. R. Van den Broeke, C. H. Reijmer, and P. Kuipers Munneke (2012), Surface and snowdrift sublimation at Princess Elisabeth station, East Antarctica, Cryosphere, 6(4), 841-857, doi:10.5194/tc-6-841-2012.

Thomas, E. R., G. J. Marshall, and J. R. McConnell (2008), A doubling in snow accumulation in the western Antarctic Peninsula since 1850, Geophys. Res. Lett., 35, L01706, doi:10.1029/2007GL032529.

Van den Broeke, M. R., W. J. van de Berg, E. van Meijgaard, and C. H. Reijmer (2006), Identification of Antarctic ablation areas using a regional atmospheric climate model, J. Geophys. Res., 111, D18110, doi:10.1029/2006JD007127.

Van Lipzig, N., E. van Meijgaard, and J. Oerlemans (2003), The effect of temporal variations in the surface mass balance and temperature inversion strength on the interpretation of ice core signals, J. Glaciol., 48(163), 611-621.

Winther, J. G., M. N. Jespersen, and G. E. Liston (2001), Blue-ice areas in Antarctica derived from NOAA AVHRR satellite data, J. Glaciol., 47(157), 325-334. 